9 Schmoeckel C, Bockelbrink A, Bockelbrink H, Kistler H, Braun-Falco O. Low- and high-risk malignant melanoma; III. Prognostic significance of the resection margin. Eur $\mathcal{f}$ Cancer Clin Oncol 1983;19:245-9.

10 Ackerman AB, Scheiner AM. How wide and deep is wide and deep enough? A critique of surgical practice in excisions of primary cutaneous malignant melanoma. Hum Pathol 1983;14:743-4.

11 Day CL, Harrist TJ, Gorstein F, et al. Malignant melanoma; prognostic significance of "microscopic satellites" in the reticular dermis and subcutaneous fat. Ann Surg 1981;194: 108-12.

12 Elder DE, Guerry D, Heiberger RM, et al. Optimal resection margin for cutaneous malignant melanoma. Plast Reconstr Surg 1983;71:66-72.

13 Rampen FHJ. Melanoma of the skin; the problem of resection margins. Eur $f$ Cancer $1981 ; 17: 589-90$.

14 McNeer G, Cantin J. Local failure in the treatment of melanoma. AfR 1967;99:791-808. Day CL, Mihm MC, Sober AJ, Fitzpatrick TB, Malt RA. Narrower margins for clinical stage I malignant melanoma. $N$ Engl $\mathcal{F}$ Med 1982;306:479-82.

列 $30-4$.

17 Rogers GS, Kopf AW, Rigel DS, et al. Effect of anatomical location on prognosis in patients with clinical stage I melanoma. Arch Dermalol 1983;119:644-9.

\section{Do minor affective disorders need medication?}

Minor affective disorders usually present with symptoms of anxiety or depressed mood. Difficult life events are often important in causing these, ${ }^{12}$ and improvement tends to occur within six to 12 months. ${ }^{34}$ These disorders may not be associated with a severe disturbance of behaviour or a disruption of normal life, but they do cause considerable distress and are particularly frequent among patients who consult general practitioners.

Over the past 20 years psychotropic drugs, especially minor tranquillisers, non-barbiturate sedatives, and antidepressants, have become increasingly popular in the treatment of patients with minor affective disorders. Nevertheless, both the value and the dangers of this form of treatment are still uncertain. Though they appear to be safer than alcohol or self prescribed medication, ${ }^{6}$ their long term use may be associated with serious disadvantages and may not even be effective.? Indeed, some studies have suggested that in patients with moderate or low levels of anxiety psychotropic drugs are no better than placebo. ${ }^{8}$ The potential hazards of psychotropic drugs include a proneness to road traffic accidents, ${ }^{9}$ excessive dependence with adverse reactions on withdrawal, ${ }^{10}$ deliberate self poisoning, ${ }^{11}$ aggressive outbursts, ${ }^{12}$ and interaction with alcohol. ${ }^{13}$ In addition, the cost to the National Health Service is immense, ${ }^{14}$ for these are probably the most frequently prescribed drugs in general practice. ${ }^{15}$

So which patients really benefit from psychotropic drugs, and what will happen if these drugs are not prescribed? New evidence is provided by Catalan $e t$ al, who examined the effects of withholding anxiolytic drugs from patients who would normally have been given them by their general practitioners. ${ }^{16}$ Patients who had not consulted their general practitioner for a psychiatric disorder during the preceding three months and who had not received psychotropic drugs during this time were allocated randomly to treatment either with anxiolytic drugs or by brief counselling. The latter included explanation of symptoms, exploration of underlying problems and ways of dealing with them, as well as reasons for not prescribing. The two groups were compared for psychiatric state, social adjustment, and satisfaction with treatment as well as the use of prescribed and nonprescribed medication during the seven months of the study. The result was striking: the two groups of patients made similar and parallel improvement in all measures of outcome. Neither group increased its consumption of alcohol, tobacco, or non-prescribed drugs, and the group not treated with drugs did not appear to make greater demands on the general practitioners' time. About a third of the patients remained unimproved, the more severely disturbed patients tending to do less well.

Thus simple counselling may be as effective as treatment with psychotropic drugs in the management of minor affective disorders, and it is not appreciably more time consuming. The principles of counselling may be used to good effect by all doctors: we need to listen, perhaps advise about symptoms, and recognise that these may be a reaction to upsetting events rather than indices of endogenous disease. Perhaps the most essential ingredient of this approach is to realise how effective it may be. Nevertheless, it is unrealistic to assume that such insight will in itself be sufficient to change established clinical practice-which derives as much from patient expectation as overestimation of the efficacy of psychotropic drugs-and alternative strategies must be adopted.

Easy access to psychiatric advice, particularly in the health centre, and provision of treatment programmes for withdrawal of psychotropic drugs in patients who are unable to discontinue them without specialist help are within the remit of the psychiatric service. Gradual withdrawal of drugs under the supervision of general practitioners and with the back up of patient self help groups may reduce the amounts of drugs taken. ${ }^{17}$ Psychiatrists might show a lead by using psychotropic drugs less often and by discouraging their use when advising others. Drug advertising might become less preoccupied with the wisdom of persuading doctors to adopt the newest preparation, and instead emphasise the need for caution before prescribing psychotropics. Guidance is also required on when and how to finish a course of treatment, even if symptoms have not resolved completely, to avoid a drift into ineffective chronic prescription of psychotropic drugs. Above all, however, we must realise that the greatest need of patients with minor affective disorders is to talk, however briefly, about themselves and the difficulties that they face. To be able to listen to them is one of the most important skills which a doctor should possess, and one which may also be shared with other professionals. More active intervention may amount to meddlesome and at times harmful interference.

H G MORGAN

Professor of Mental Health,

University of Bristol,

Bristol BS2 8DZ

\footnotetext{
1 Cooper B. Clinical and social aspects of chronic neurosis. Proceedings of the Royal Society of Medicine 1972;65:19-22. pooper B, Sylph J. Life events and the
practice. Psychol Med 1973;13:421-35. practice. Psychol Med 1973;13:421-35.

method of case identification. $\mathrm{Br}$ Med 7 1970;

general practice. Psychol Med 1981;11:535-50. munity. Psychol Med 1976;6:565-9. Anonymous. Benzodiazepines: use over-use, misuse, abuse? [Editorial]. Lancet 1973;i:1101-2. Committee on the Review of Medicines. Systematic review of the benzodiazepines. Guidelines for data sheets on diazepam, chlordiazepoxide, medazepam, clorazepate, lorazepam,

8 Johnstone EC, Owens DCG, Frith CD, et al. Neurotic illness and its response to anxiolytic and antidepressant treatment. Psychol Med 1980;10:321-8.

Skegg DCG, Rich

Petursson H, Lader MH. Withdrawal from long term benzodiazepine treatment. Br Med f 1981 283:643-5.

11 Morgan HG, Barton J, Pottle S, Pocock H, Burns-Cox CJ. Deliberate self-harm: a follow up study of 279 patients. Br $\mathcal{F}$ Psychiatry 1976;128:361-8.

12 Goldney RD. Paradoxical reaction to a new minor tranquilliser. Med f Aust 1977;i:139-40.

13 Hayes SL, Pablo G, Radomski T, Palmer RF. Ethanol and oral diazepam abortion. $N$ Engl $\mathcal{J}$ Med 1977;296:186-9.

14 Trethowan WH. Pills for personal problems. Br Med $\mathcal{F}$ 1975; iii:749-51.

5 Skegg DCG, Doll R, Perry J. Use of medicines in general practice. Br Med f 1977;i:1561-3.

16 Catalan J, Gath D, Bond A, Martin P. The effects of non-prescribing of anxiolytics in general practice. II. Factors associated with outcome. Br $\mathcal{F}$ Psychiatry 1984;144:603-10.

17 Jones LG. Psychotropic drug prescribing in general practice. Bristol University, 1983. (MS hesis.)
} 